\title{
Eskişehir Ekolojik Koşullarında Farklı Karabuğday (Fagopyrum esculentum Moench) Çeşidinde Uygun Ekim Normunun Belirlenmesi
}

\author{
*Duran KATAR ${ }^{1}$ \\ Nimet KATAR ${ }^{2}$ \\ ${ }^{1}$ Eskişehir Osmangazi Üniversitesi, Ziraat Fakültesi, Tarla Bitkileri Bölümü, Eskişehir \\ ${ }^{2}$ Eskişehir Osmangazi Üniversitesi, Fen Bilimleri Enstitüsü, Eskişehir \\ *Sorumlu yazar e-posta (Corresponding author e-mail): durankatar@gmail.com
}

Geliş Tarihi (Received): 06.02.2017

Kabul Tarihi (Accepted): 21.04.2017

Öz

Bu denemede farklı ekim sıklıklarının Aktaş ve Güneş karabuğday çeşitlerinde verim ve verim unsurları üzerine etkileri araştırılmıştır. Deneme tesadüf bloklarında faktöriyel deneme deseninde üç tekerrürlü olarak Eskişehir iklim koşullarında ve 2013-2014 yıllarında yürütülmüş olup, 4 farklı ekim sıklığı (6, 8, 10 ve 12 kg/ da) denenmiştir. Deneme sonuçlarına göre bitki boyunda, bitki başına salkım sayısında ve tohum veriminde en yüksek değerler Aktaş çeşidinden elde edilmiştir. En yüksek bitki boyu, bitki başına salkım sayısı, 1000 tohum ağırlığı ve bitki başına tohum verimi $6 \mathrm{~kg} / \mathrm{da}$ ekim normundan ve en yüksek tohum verimi (kg/da) ise $12 \mathrm{~kg} / \mathrm{da}$ ekim normundan elde edilmiştir.

Anahtar Kelimeler: Karabuğday çeşitleri, Fagopyrum esculentum Moench, ekim normları

\section{Determination of Sowing Rates of Different Buckwheat (Fagopyrum esculentum Moench) Cultivars Under Eskişehir Ecological Conditions}

\begin{abstract}
The aim of this study was to determine the effect of different sowing rates on yield and some yield components in two buckwheat cultivars (Aktaş and Güneş). Study was carried out in randomized factorial block design with three replications under Eskişehir climatic conditions during the years of 2013-2014. Four sowing rates $(6,8,10$ and $12 \mathrm{~kg} / \mathrm{da})$ were applied. Results showed that sowing rates had significant effect on plant height, cluster number per plant and seed yield giving higher values in Aktaş cultivar. Once, $6 \mathrm{~kg} /$ da seed rate gave the highest plant height, cluster number per plant, 1000 seed weight and seed yield per plant; the highest seed yield was obtained from $12 \mathrm{~kg} / \mathrm{da}$ sowing rate.
\end{abstract}

Keywords: Buckwheat cultivars, Fagopyrum esculentum Moench, sowing rates

\section{Giriş}

$\mathrm{K}$ arabuğday (Fagopyrum esculentum Moench); Polygonaceae familyasına ait, tek yıllık ve otsu bir bitkidir (Inamullah ve ark 2012). Fagopyrum cinsinin dünyada yaklaşık 15 kadar türü yayılış göstermekle birlikte bunlardan sadece yaygın karabuğday (Fagopyrum esculentum Moench) ve tatar karabuğdayının (Fagopyrum tataricum L. Gaertn.) kültürü yapılmaktadır (Ohnishi 1994). Bitki hızı gelişme özelliğine sahip olup, 1014 hafta gibi kısa sürede olgunlaşarak hasat olgunluğuna gelmektedir (Janos ve Gocs 2009). Bu da bitkiyi vejetasyon süresi kısa olan bölgeler için önemli bir alternatif kültür bitkisi kılmanın yanı sıra vejetasyon süresi uzun olan bölgeler için ise ikinci ürün olarak faydalanma imkânı sağlamaktadır (Min ve ark 2004; Inamullah ve ark 2012).

Bitki çok yönlü kullanıma sahip olup, tohumları insan ve hayvan beslenmesinde kullanıldığı gibi ayrıca tıbbi amaçlarla da faydalanılabilmektedir (Janos ve Gocs 2009). Bitkinin tohumlarında glutenin bulunmaması çölyak hastalarının beslenmesinde farklı şekillerde kullanılmasına imkan sağlamaktadır (Kim ve ark 2004; Okudan 2015). Bitkinin tohumunda protein oranının yüksek olması 
(\%18) ve proteinin esansiyel aminoasitlerce (lisin, treonin, triptofan vb.) zengin olması sağlıklı beslenme açısından da kullanımının yaygınlaşmasına neden olmuştur (Bonafaccia ve ark 2003; Anonim 2015). Bitkinin tohumunda ve vejetatif aksamında bulunan fenolik antioksidanlar, aromatik bileşikler ve fagopirin gibi biyoaktif metabolitler nedeniyle tıbbi amaçlarla da farklı hastalıkların tedavisinde kullanılmaktadır (Kreft ve ark 1999; Anonim 2015). Ayrıca karabuğday bitkisi tarımsal üretimde iyi bir örtü ve yeşil gübre bitkisi olarak da kullanılmaktadır (Janos ve Gocs 2009).

Bitkisel üretimde verim ve kalite, üretimde kullanılan bitkisel materyalin genotipi, üretimin yapıldığı bölgenin iklim ve toprak koşulları ve yetiştiricilik uygulamaları tarafından belirlenmektedir. Yetiştiricilikuygulamalarından birim alana atılacak tohumluk miktarı elde edilecek ürünün verim ve kalitesi üzerinde önemli bir etkiye sahiptir. Birim alana atılacak tohumluk miktarının optimum olması birim alanda fazla bitkinin oluşumunu engelleyerek, bitkiler arasında oluşacak olan ışık, su ve bitki besin elementi rekabetinin olumsuz etkisini ortadan kaldırmaktadır. Bu da üretimde verim ve kalite artışına neden olmaktadır (Janos ve Gocs 2009; Bagheri ve ark 2011). Herhangi bir kültür bitkisinde birim alanda bulunacak olan optimum bitki sayısı, üretimde kullanılan çeşidin genetik özelliklerine, üretimin yapılacağı bölgenin iklim ve toprak özelliklerine ve üretim sistemlerine bağlı olarak değişiklik göstermektedir (Özer 2003). Bu nedenle kültür bitkileri için birim alanda bulunması gereken optimum bitki sayıları lokasyonlar bazında yapılacak olan yerel çalışmalarla belirlenmesi gerekmektedir. Janos ve Gocs

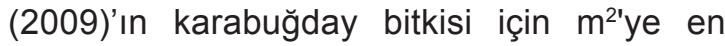
uygun bitki miktarını belirlemek için yapmış oldukları çalışmada en yüksek tohum verimini (196.3 kg/da) m²'ye 375 bitkiden elde etiklerini bildirmişlerdir. Yavuz ve ark. (2016)'nın Aydın ekolojik koşullarında yürütmüş oldukları çalışmada karabuğday üretiminde en yüksek dane verimini $10 \mathrm{~kg} / \mathrm{da}$ tohumluk veriminden alınmasına rağmen 8 kg/da'dan sonraki artan tohumluk miktarının istatistiksel olarak verimi artışı sağlamadığını bildirmişlerdir. Bitki üzerinde ülkemizde yürütülen çalışmalar henüz başlangıç aşamasında olup, üretimiyle ilgili bilgi ihtiyacının karşılanabilmesi bakımından bitki üzerinde yürütülecek agronomik çalışmalara ihtiyaç bulunmaktadır. Bu çalışma ile, Eskişehir ekolojik koşullarında iki farklı karabuğday çeşidi için en uygun ekim normlarının belirlenmesi amaçlanmıştır.

\section{Materyal ve Yöntem}

Araştırmada materyal olarak Bahri Dağdaş Uluslararası Tarımsal Araştırma Enstitüsü tarafından geliştirilen Aktaş ve Güneş karabuğday çeşitleri kullanılmıştır.

\section{Deneme Yerinin Toprak ve İklim Özellikleri}

Bu çalışma 2013 ve 2014 yıllarında ESOGÜ Ziraat Fakültesi Araştırma ve Uygulama tarlasında yürütülmüştür. Araştırmanın yapıldığı deneme alanı killi tınlı bünyeye sahip olup, hafif alkali ( $\mathrm{pH} 7.7-8.1)$ bir yapı arz etmektedir. Hafif tuzlu (\%0.38) ve orta düzeyde kireçli (\%5.67) olan deneme alanı toprağı organik madde içeriği (\%1.5) bakımından da yetersizdir. Faydalanılabilir fosfor düzeyi (4.51 $\left.\mathrm{P}_{2} \mathrm{O}_{5} \mathrm{~kg} / \mathrm{da}\right)$ az iken, potasyum $\left(243 \mathrm{~K}_{2} \mathrm{O} \mathrm{kg} / \mathrm{da}\right)$ yeterli düzeydedir (Çizelge 1).

Tarla çalışmasının yürütüldüğü 2013 ve 2014 yılları içerisinde bitkinin vejetasyon döneminde düşen yağış miktarları uzun yıllarla kıyaslanarak incelendiğinde daha düşük olduğu görülebilmektedir. Bölgenin bu döneme ait uzun yıllar yağış ortalaması 150.8 mm iken, 2013 yılı 82.8 mm ve 2014 yılında ise $120.5 \mathrm{~mm}$ olarak gerçekleşmiştir. Sıcaklık ortalamaları ise uzun yıllarla paralel seyretmiştir (Çizelge 2).

Çizelge 1. Deneme yeri topraklarının bazı fiziksel ve kimyasal özellikleri.(*)

Table 1. Some physical and chemical properties of the experiment site soil

\begin{tabular}{lccccccc}
\hline $\begin{array}{c}\text { Toprak } \\
\text { Derinliği } \\
(\mathrm{cm})\end{array}$ & $\begin{array}{c}\text { Toplam } \\
\text { Tuz }(\%)\end{array}$ & $\begin{array}{c}\text { Organik } \\
\text { Madde } \\
(\%)\end{array}$ & Kireç & $\begin{array}{c}\text { Fosfor } \\
\left(\mathrm{P}_{2} \mathrm{O}_{5} \mathrm{~kg} / \mathrm{da}\right)\end{array}$ & $\begin{array}{c}\text { Bitkiye Yarayışlı } \\
\left(\mathrm{K}_{2} \mathrm{O} \text { kg/da) }\right.\end{array}$ & Bünye & $\mathrm{pH}$ \\
\hline $0-40$ & 0.38 & 1.5 & 5.46 & 4.51 & 243 & Killi-Tınlı & $7.6-8.2$ \\
\hline *Analizler, Geçit Kuşağı Tarımsal Araştırma Enstitüsü toprak analiz laboratuvarında yaptırılmıştır. \\
*The analyzes were carried out in the soil analysis laboratory of the Eskişehir Transitional Zone Agricultural Research \\
Institute
\end{tabular}



Moench) Cultivars Under Eskişehir Ecological Conditions"

Çizelge 2. Eskişehir İlinin 2013, 2014 ve Uzun Yıllara Ait Bazı İklim Verileri Table 2. Some climate data of Eskisehir province in 2013, 2014 and long years

\begin{tabular}{|c|c|c|c|c|c|}
\hline Yıllar/Aylar & Nisan & Mayıs & Haziran & Temmuz & Toplam/Ort. \\
\hline \multicolumn{6}{|c|}{ Toplam Yağış (mm) } \\
\hline 2013 & 30.9 & 18.5 & 31.3 & 2.1 & 82.8 \\
\hline 2014 & 15.2 & 27.2 & 70.6 & 7.5 & 120.5 \\
\hline $1975-2010$ & 50.0 & 49.7 & 35.1 & 16.0 & 150.8 \\
\hline \multicolumn{6}{|c|}{ Ortalama Sıcaklık ( $\left.{ }^{\circ} \mathrm{C}\right)$} \\
\hline 2013 & 10.8 & 18.2 & 20 & 21.6 & 17.65 \\
\hline 2014 & 11.5 & 15.1 & 18.5 & 22.6 & 16.93 \\
\hline $1975-2010$ & 11.3 & 16.0 & 20.2 & 23.5 & 17.75 \\
\hline \multicolumn{6}{|c|}{ Ortalama Nispi Nem (\%) } \\
\hline 2013 & 63.2 & 51.5 & 53.9 & 51.9 & 55.13 \\
\hline 2014 & 62.7 & 66.2 & 66.9 & 58.6 & 63.6 \\
\hline $1975-2010$ & 60.8 & 60.3 & 59.1 & 60.0 & 60.05 \\
\hline
\end{tabular}

*Eskişehir Meteoroloji Bölge Müdürlüğünden alınmıştır.

*Eskişehir Regional Directorate of Meteorology

Deneme, tesadüf bloklarında faktöriyel deneme (bölünmüş parseller) desenine göre üç tekerrürlü olarak kurulmuştur. Her parsel $5 \mathrm{~m}$ uzunluğunda ve $1.5 \mathrm{~m}$ genişliğinde (her parselde altı sıra) olup, parsel alanı 7.5 $\mathrm{m}^{2}$ 'dir. Parsellere ekimler sıra arası mesafeler $25 \mathrm{~cm}$ olacak şekilde farklı ekim normları kullanılarak ve ekim derinliği $3-4 \mathrm{~cm}$ olacak şekilde 07.04.2013 ve 11.04.2014 tarihlerinde elle yapılmıştır. Çalışmada kullanılan 2 karabuğday çeşidi (Aktaş ve Güneş) ana parsellere ve 4 farklı ekim normu $(6,8,10$ ve $12 \mathrm{~kg} / \mathrm{da}$ ) ise alt parsellere gelecek şekilde yerleştirilmiştir (Acar ve ark 2012). Parsellerde herhangi bir ek gübreleme yapılmamıştır. Bitkiler çıkışlarını tamamladıktan sonra yabancı ot mücadelesi amaçlı bir çapalama yapılmıştır. Biri haziran ayının ilk yarısında ve diğeri haziran ayının sonuna doğru olacak şekilde 2013 ve 2014 yıllarında parseller ikişer defa sulanmıştır. Deneme parsellerine hastalık ve zararlılarla mücadele amaçlı herhangi bir uygulama yapılmamıştır. Denemelerin hasadı 15.07.2013 ve 17.07.2014 tarihlerinde yapılmıştır. Hasatta, parsel kenarlarından birer sıra ve sıraların baş ve sonlarından 0.5 m'si kenar tesiri olarak atılmıştır. Tek bitki değerleri, her parselden tesadüfen seçilen 10'ar bitki ölçülüp tartılarak belirlenmiştir. Dekara tohum verimleri parsel verimleri üzerinden hesaplanmıştır.

Araştırma sonunda elde edilen verilerin Varyans Analizi, tesadüf bloklarında bölünen bölünmüş deneme desenine göre yapılmıştır.
Uygulamalar arasındaki farklılıkların önem düzeylerini belirleyebilmek amacıyla LSD Testi kullanılmıştır (Düzgüneş ve ark 1987). Tüm istatistiki hesaplamalar bilgisayarda MSTAT-C paket programı kullanılarak yapılmıştır.

\section{Bulgular ve Tartışma}

Bitkisel üretimde elde edilecek olan ürünün verim ve kalitesi üretimde kullanılacak olan tohumlukların genotipi ile birlikte üretimin yapıldığıbölgeninekolojikkoşullarıveyetiştiricilik uygulamaları tarafından belirlenmektedir (Geçit ve ark 2009; Kaleem ve ark 2010; Şehirali ve Özgen 2010). Bu nedenle Islah edilerek tescil ettirilmiş olan çeşitlerin farklı ekolojik koşullarda denenerek performanslarının belirlenmesi bölge üreticilerinin çeşit tercihinde büyük önem taşımaktadır. Optimum verim ve kaliteye ulaşılabilmesi açısından sadece bölge için uygun olan çeşidin belirlenmesi yetmez bu çeşit için üretimin yapılacağı bölgede yapılacak olan denemelerle en uygun yetiştiricilik uygulamalarının da belirlenmesine intiyaç bulunmaktadır. Bilindiği gibi en önemli yetiştiricilik uygulamalarından biriside birim alana atılacak tohumluk miktarı olup, bu uygulama birim alanda optimum sayıda bitki bulunmasını sağlayarak sonuçta ürünün verim ve kalitesini olumsuz yönde etkileyen bitkiler arasındaki rekabeti engellemektedir (Sobhani ve ark 2012). Bu nedenle yerel düzeyde yapılacak olan çalışmalarla birim alana atılacak en uygun tohumluk miktarlarının belirlenmesi gerekmektedir. 


\section{Bitki Boyu (cm)}

İki farkı karabuğday çeşidi ve dört farklı ekim normu kullanılarak Eskişehir koşullarında iki yıl süreyle yürütülen çalışmanın sonuçları yılların ve ekim normlarının bitki boyu üzerinde istatistik anlamda önemli düzeyde etkili olduğunu göstermiştir. Diğer taraftan çeşitlerin ve interaksiyonların ise bitki boyu üzerinde önemli bir etkisi tespit edilememiştir. Yılların bitki boyu üzerine etkisi incelendiğinde 2014 yılı $(77.03 \mathrm{~cm}) 2013$ yilına $(50.75 \mathrm{~cm})$ kıyasla daha yüksek bitki boyu değerini verdiği görülmüştür (Çizelge 3). Bu durum en basit şekilde yıllar arasında yaşanan yağış farkıyla açıklanması mümkündür. Çünkü 2014 yılı 2013 yılına kıyasla yaklaşık $48 \mathrm{~mm}$ dolayında daha fazla yağış almıştır (Çizelge 2). Bu yağışın büyük bir kısmı da bitkinin vejetatif gelişim döneminde gerçekleştiği için bitki boyunda artışa neden olmuştur.

Ekim normları arasında ise en yüksek bitki boyu en az tohumun atıldığı $(6 \mathrm{~kg} / \mathrm{da})$ ekim normundan $61.81 \mathrm{~cm}$ ile alınırken, en düşük değer ise en çok tohumluğun ( $12 \mathrm{~kg} / \mathrm{da})$ atıldığı parselden $59.71 \mathrm{~cm}$ ile alınmıştır (Çizelge 3). $\mathrm{Bu}$ durumda birim alana gereğinden daha az atılan tohumluğun bitki boyunda artışa neden olduğunu fakat birim alandaki bitki sayısı arttıkça aynı alandan beslenecek ve yaşamını sürdürecek olan arasındaki rekabet artmakta ve bu da bitkilerin vejetatif gelişimi sınırlandırarak bitki boyunu olumsuz yönde etkilemiştir. Genel ortalama olarak elde etmiş olduğunuz bitki boyuna ait değerimiz $63.89 \mathrm{~cm}$ olup, Okudan (2015)'ın bildirdiği 44.7-75.3 cm değeri, Yavuz ve ark (2016)'nın bildirdiği $64,76-71,19 \mathrm{~cm}$ ve Topal ve ark (2012)'nın bildirdiği 62,23-85,66 cm değerleri ile uyum gösterirken, Bagheri ve ark. (2011)'nın bildirdiği 101.4-114.3 cm değerinden ise bir miktar düşük kalmıştır.

\section{Bitki Başına Dal Sayısı (adet/bitki)}

Yürütülen çalışmada çeşitlerin ve ekim normlarının bitki başına dal sayısı üzerinde istatistiki anlamda önemli bir etkide bulunmazken, yılların bu parametre üzerinde önemli düzeyde etkili olduğu görülmüştür (Çizelge 3). Bitki başına yan dal sayısı üzerine yılların etkisi incelendiğinde 2014 yılının değerleri (2.40 adet/bitki) 2013 yılına (2.01 adet/bitki) kıyasla daha yüksek bulunmuştur. Bu durumda 2014 yılının Mayıs ve Haziran aylarında alınan yağışın 2013 yılının aynı aylarında alınan yağışa kıyasla iki katına yakın yüksek olmuş olmasıyla açıklanabilir (Çizelge 2). Her ne kadar çeşitler arasında dal sayısı bakımından istatistiki anlamda önemli bir fark bulunmamış olsa da, yılların ortalaması itibariyle bakıldığında 2.40 adet/ bitki ile Güneş çeşidi Aktaş (2.30 adet/bitki) çeşidinden daha yüksek değer vermiştir. Bu durumda genotipin dallanma özelliği üzerine olan etkisiyle açıklanabilir. Aynı şekilde ekim normları da her ne kadar dal sayısı üzerinde istatistiki anlamda önemli bir fark oluşturmamış olsa da birim alana artan bitki sayısına paralel olarak dal sayısında bir azalış olduğu görülmüş olup, en yüksek dal sayısı birim alana en az tohumun ekildiği $(6 \mathrm{~kg} / \mathrm{da})$ parselden $2.47 \mathrm{adet} /$ bitki ile alınırken en düşük değer ise 2.21adet/ bitki ile $10 \mathrm{~kg} / \mathrm{da}$ ekim normundan alınmıştır. Bu da birim alana artan bitki sayısının etkisiyle oluşan rekabetle açıklanabilir. Bitki başına dal sayısı değerlerimiz (1.71-3.13 adet/bitki) Tseng ve Huang (1992)'ın bildirdiği 3.2-4.1 adet/bitki değerinden düşük kaldığı görülmüştür. bitki)

Bitki Başına Çiçek Salkımı Sayısı (adet/

Bitki başına çiçek salkımı sayıları bakımından elde edilen değerler incelendiğinde, bu parametre üzerinde yılların, ekim normunun ve yıl $\times$ çeşit $\times$ ekim normu interaksiyonunun istatistiki anlamda etkili olduğu görülmüştür (Çizelge 3). Yıllar bakımından karşılaştırma yapıldığında daha önce incelen diğer iki özellikte olduğu gibi bitki başına çiçek salkımı sayısında da 2014 (14.33 adet/bitki) yılından 2013 (9.97 adet/bitki) yılına kıyasla daha yüksek değer elde edilmiştir. Ekim normu bakımından bu parametre değerleri incelendiğinde ise birim alana en az tohumun atıldığı $6 \mathrm{~kg} / \mathrm{da}$ ekim normundan en yüksek değer 13.96 adet/bitki ile elde edilmişken en düşük değer ise $10 \mathrm{~kg} / \mathrm{da}$ ekim normunun kullanıldığı parsellerden (10.89 adet/bitki) elde edilmiştir. Bu da birim alana artan bitki sayısının bitki başına dal sayısında ve buna bağlı olarak da çiçek salkımı sayısı üzerindeki olumsuz etkisiyle açıklanabilir.

Bitki başına çiçek sayısı bakımından yıl $x$ çeşit $\times$ ekim normu interaksiyonu incelendiğinde ise en yüksek değer Aktaş çeşidinin 2014 yilından ve $6 \mathrm{~kg} / \mathrm{da}$ ekim normundan 17.56 adet/bitki ile alınmışken, en düşük değer 8.30 adet/bitki ile Güneş çeşidinin 2013 yılının 10 kg/ da ekim normundan alınmıştır (Çizelge 3). Bu da çeşitlerin yıllara bağı olarak bu parametre bakımından farklı tepki gösterdiğini ortaya koymaktadır. Bitki başına çiçek salkımı sayısı değerlerimiz (8.30-17.56 adet/bitki) Tseng ve Huang (1992)'ın bildirdiği 14-30 adet/bitki değerinden düşük kalmıştır. 
Katar and Katar "Determination of Sowing Rates of Different Buckwheat (Fagopyrum esculentum Moench) Cultivars Under Eskişehir Ecological Conditions"

Çizelge 3. Farklı ekim normlarının karabuğday bitkisinin verim ve verim unsurları üzerine etkisine ait ortalama değerler ve varyans analizi

Table 3. Mean values and variance analysis of the effects of different sowing rates on the yield and yield components

\begin{tabular}{clccccc}
\hline \multicolumn{7}{c}{ Bitki Boyu $(\mathrm{cm})$} \\
\hline \multirow{2}{*}{ Yıllar } & Çeşitler & $6 \mathrm{~kg} / \mathrm{da}$ & $8 \mathrm{~kg} / \mathrm{da}$ & $10 \mathrm{~kg} / \mathrm{da}$ & $12 \mathrm{~kg} / \mathrm{da}$ & Ortalama \\
\hline \multirow{3}{*}{2013} & Aktaş & 55.63 & 53.10 & 48.27 & 47.97 & 51.24 \\
& Güneş & 54.37 & 51.83 & 48.10 & 46.70 & 50.25 \\
& Ortalama & 55.00 & 52.47 & 48.18 & 47.33 & $50.75 \mathrm{~B}$ \\
\hline \multirow{3}{*}{2014} & Aktaş & 83.73 & 79.10 & 81.13 & 78.20 & 80.54 \\
& Güneş & 77.50 & 77.77 & 72.83 & 65.97 & 73.52 \\
& Ortalama & 80.62 & 78.43 & 76.98 & 72.08 & $77.03 \mathrm{~A}$ \\
\hline \multirow{2}{*}{ Yılların ort.olarak } & Aktaş & 69.68 & 66.10 & 64.70 & 63.08 & 65.89 \\
& Güneş & 65.93 & 64.80 & 60.47 & 56.33 & 61.88 \\
\hline Genel Ortalama & & $67.81^{\mathrm{A}}$ & $65.45^{\mathrm{AB}}$ & $62.58^{\mathrm{BC}}$ & $59.71^{\mathrm{C}}$ & 63.89 \\
\hline
\end{tabular}

F: Yıl:408.95**; Çeşit: 1.95ns; Yıl×Çeşit: 1.11ns; E.Normu: 7.65**; Yıl×E.Normu: 0.48ns;

Çeşit×E.Normu: 0.78ns; Y॥l×Çeşit×E.Normu: 0.85ns

\begin{tabular}{|c|c|c|c|c|c|c|}
\hline & & & sına Dal & & & \\
\hline & & & m Norms & & & \\
\hline Yıllar & Çeşitler & $6 \mathrm{~kg} / \mathrm{da}$ & $8 \mathrm{~kg} / \mathrm{da}$ & $10 \mathrm{~kg} / \mathrm{da}$ & $12 \mathrm{~kg} / \mathrm{da}$ & Ortalama \\
\hline & Aktaş & 1.98 & 1.99 & 1.71 & 2.07 & 1.94 \\
\hline 2013 & Güneş & 2.40 & 1.83 & 2.17 & 1.90 & 2.07 \\
\hline & Ortalama & 2.19 & 1.91 & 1.94 & 1.98 & $2.01 \mathrm{~b}$ \\
\hline & Aktaş & 2.59 & 2.77 & 2.53 & 2.73 & 2.66 \\
\hline 2014 & Güneş & 2.90 & 3.13 & 2.43 & 2.47 & 2.73 \\
\hline & Ortalama & 2.75 & 2.95 & 2.48 & 2.60 & $2.70 \mathrm{a}$ \\
\hline Yılların ort.olarak & Aktaş & 2.29 & 2.38 & 2.12 & 2.40 & 2.30 \\
\hline & Güneş & 2.65 & 2.48 & 2.30 & 2.18 & 2.40 \\
\hline Genel Ortalama & & 2.47 & 2.43 & 2.21 & 2.29 & 2.35 \\
\hline
\end{tabular}

F: Yıl: 19.75*; Çeşit: 0.24ns; Y॥l×Çeşit: 0.02ns; E.Normu: 1.12ns; Yıl× E.Normu: 1.09ns;

Çeşit× E.Normu: 1.15ns; Yıl×Çeşit× E.Normu: 0.96ns

C.V.(\%): $24.29 ;$ L.S.D.(\%): Yıl:0.67

\begin{tabular}{clccccc}
\hline C.V.(\%): 24.29; & L.S.D.(\%): Yıl:0.67 & \multicolumn{7}{c}{ Bitki Başına Salkım Sayısı } \\
\hline \multirow{2}{*}{ Yıllar } & Çeşitler & $6 \mathrm{~kg} / \mathrm{da}$ & $8 \mathrm{~kg} / \mathrm{da}$ & $10 \mathrm{~kg} / \mathrm{da}$ & $12 \mathrm{~kg} / \mathrm{da}$ & Ortalama \\
\hline \multirow{2}{*}{2013} & Aktaş & $9.03 \mathrm{~A}$ & $9.93 \mathrm{~A}$ & $9.29 \mathrm{~A}$ & $10.84 \mathrm{~A}$ & 9.77 \\
& Güneş & $14.53 \mathrm{~A}$ & $8.50 \mathrm{~B}$ & $8.30 \mathrm{~B}$ & $9.36 \mathrm{~B}$ & 10.17 \\
& Ortalama & 11.78 & 9.22 & 8.79 & 10.10 & $9.97 \mathrm{~b}$ \\
\hline \multirow{2}{*}{2014} & Aktaş & $17.56 \mathrm{~A}$ & $15.03 \mathrm{AB}$ & $13.87 \mathrm{AB}$ & $12.90 \mathrm{~B}$ & 14.84 \\
& Güneş & $14.73 \mathrm{~A}$ & $15.43 \mathrm{~A}$ & $12.10 \mathrm{~A}$ & $13.03 \mathrm{~A}$ & 13.83 \\
& Ortalama & 16.15 & 15.23 & 12.98 & 12.97 & $14.33 \mathrm{a}$ \\
\hline Yılların ort.olarak & Aktaş & 13.30 & 12.48 & 11.58 & 11.87 & 12.31 \\
& Güneş & 14.63 & 11.97 & 10.20 & 11.20 & 12.00 \\
\hline Genel Ortalama & & $13.96 \mathrm{~A}$ & $12.23 \mathrm{AB}$ & $10.89 \mathrm{~B}$ & $11.53 \mathrm{~B}$ & 12.15 \\
\hline
\end{tabular}

F: Yıl: 50.90*; Çeşit: 0.27ns; Yll×Çeşit: 1.41ns; E.Normu: 7.02**; Yıl× E.Normu: 1.67ns;

Çeşit× E.Normu: 1.34ns; Yı×Çeşit× E.Normu: 5.64**

C.V.(\%): 27.55; L.S.D.(\%): Yıl: 2.63; E.Normu: 1.98; Y॥|×Çeşit× E.Normu: 3.96 
Katar ve Katar "Eskişehir Ekolojik Koşullarında Farklı Karabuğday (Fagopyrum esculentum Moench Çeşidinde Uygun Ekim Normunun Belirlenmesi"

Çizelge 3 devamı

Table 3 continued

\begin{tabular}{|c|c|c|c|c|c|c|}
\hline \multicolumn{7}{|c|}{ Bitki Başına Tohum Verimi } \\
\hline \multicolumn{7}{|c|}{ Ekim Normu } \\
\hline Yıllar & Çeşitler & $6 \mathrm{~kg} / \mathrm{da}$ & $8 \mathrm{~kg} / \mathrm{da}$ & $10 \mathrm{~kg} / \mathrm{da}$ & $12 \mathrm{~kg} / \mathrm{da}$ & Ortalama \\
\hline \multirow{3}{*}{2013} & Aktaş & 2.95 & 2.57 & 2.33 & 2.16 & 2.50 \\
\hline & Güneş & 2.96 & 2.59 & 1.85 & 2.52 & 2.48 \\
\hline & Ortalama & 2.96 & 2.58 & 2.09 & 2.34 & 2.49 \\
\hline \multirow{3}{*}{2014} & Aktaş & 4.17 & 3.30 & 2.82 & 2.42 & 3.18 \\
\hline & Güneş & 3.59 & 3.37 & 3.02 & 2.90 & 3.22 \\
\hline & Ortalama & 3.88 & 3.34 & 2.92 & 2.66 & 3.20 \\
\hline \multirow{2}{*}{ Yılların ort.olarak } & Aktaş & 3.56 & 2.94 & 2.58 & 2.28 & 2.84 \\
\hline & Güneş & 3.27 & 2.98 & 2.44 & 2.71 & 2.85 \\
\hline \multicolumn{2}{|l|}{ Genel Ortalama } & $3.42 \mathrm{~A}$ & $2.96 \mathrm{~B}$ & $2.51 \mathrm{C}$ & $2.50 \mathrm{C}$ & 2.85 \\
\hline \multicolumn{7}{|c|}{ 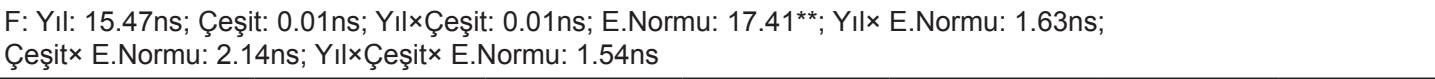 } \\
\hline \multicolumn{7}{|c|}{ C.V.(\%): $25.25 ; \quad$ L.S.D.(\%): E.Normu: 0.41} \\
\hline \multicolumn{7}{|c|}{1000 Tohum Ağırlığı (g) } \\
\hline \multicolumn{7}{|c|}{ Ekim Normu } \\
\hline Yıllar & Çeşitler & $6 \mathrm{~kg} / \mathrm{da}$ & $8 \mathrm{~kg} / \mathrm{da}$ & $10 \mathrm{~kg} / \mathrm{da}$ & $12 \mathrm{~kg} / \mathrm{da}$ & Ortalama \\
\hline \multirow{3}{*}{2013} & Aktaş & 36.07 & 35.33 & 29.96 & 25.13 & 31.62 \\
\hline & Güneş & 36.93 & 34.41 & 30.45 & 30.04 & 32.96 \\
\hline & Ortalama & $36.50 \mathrm{a}$ & $34.87 a$ & $30.20 \mathrm{~b}$ & $27.59 \mathrm{~b}$ & $32.29 a$ \\
\hline \multirow{3}{*}{2014} & Aktaş & 29.65 & 28.75 & 28.81 & 26.54 & 28.43 \\
\hline & Güneş & 29.44 & 28.22 & 25.48 & 27.32 & 27.61 \\
\hline & Ortalama & $29.54 a$ & $28.48 a$ & $27.14 a$ & $26.93 a$ & $28.02 b$ \\
\hline \multirow{2}{*}{ Yılların ort.olarak } & Aktaş & 32.86 & 32.04 & 29.38 & 25.84 & 30.03 \\
\hline & Güneş & 33.18 & 31.31 & 27.96 & 28.68 & 30.29 \\
\hline Genel Ortalama & $33.02 \mathrm{~A}$ & & $31.68 \mathrm{AB}$ & 28.67BC & $27.26 \mathrm{C}$ & 30.16 \\
\hline \multicolumn{7}{|c|}{$\begin{array}{l}\text { F: Yıl: 29.18*; Çeşit: 0.09ns; Yıl×Çeşit: 1.57ns; E.Normu: 11.76**; Yıl× E.Normu: 3.65*; } \\
\text { Çeşitx E.Normu: 1.46ns; Yıl×Çeşit× E.Normu: 0.50ns }\end{array}$} \\
\hline \multicolumn{7}{|c|}{ C.V.(\%): 13.95; L.S.D.(\%): Yıl: 3.40; E.Normu: 3.06; Yıl× E.Normu: 3.20} \\
\hline \multicolumn{7}{|c|}{ Tohum Verimi } \\
\hline \multicolumn{7}{|c|}{ Ekim Normu } \\
\hline Yıllar & Çeşitler & $6 \mathrm{~kg} / \mathrm{da}$ & $8 \mathrm{~kg} / \mathrm{da}$ & $10 \mathrm{~kg} / \mathrm{da}$ & $12 \mathrm{~kg} / \mathrm{da}$ & Ortalama \\
\hline \multirow{3}{*}{2013} & Aktaş & 54.90 & 67.63 & 95.97 & 118.90 & 84.35 \\
\hline & Güneş & 51.57 & 72.00 & 86.57 & 108.10 & 79.56 \\
\hline & Ortalama & 53.23 & 69.82 & 91.27 & 113.50 & 81.95B \\
\hline \multirow{3}{*}{2014} & Aktaş & 68.90 & 96.00 & 122.70 & 149.40 & 109.25 \\
\hline & Güneş & 63.83 & 86.07 & 107.07 & 133.20 & 97.54 \\
\hline & Ortalama & 66.37 & 91.03 & 114.88 & 141.30 & $103.40 \mathrm{~A}$ \\
\hline \multirow[t]{2}{*}{ Yılların ort.olarak } & Aktaş & 61.90 & 81.82 & 109.33 & 134.15 & $96.80 \mathrm{a}$ \\
\hline & Güneş & 57.70 & 79.03 & 96.82 & 120.65 & $88.55 b$ \\
\hline Genel Ortalama & & $59.80 D$ & $80.43 C$ & 103.08B & $127.40 \mathrm{~A}$ & 92.68 \\
\hline \multicolumn{7}{|c|}{ 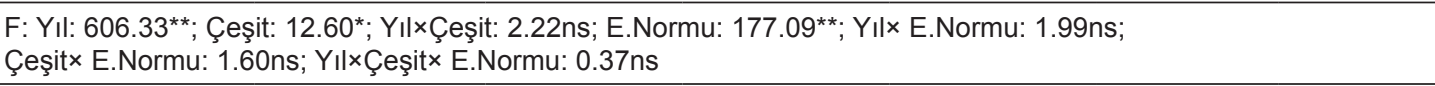 } \\
\hline C.V.(\%): $31.36 ; \quad$ L.S & D. (\%): Yıl: & it: 6.45 & mu: 8.66 & & & \\
\hline
\end{tabular}




\section{Bitki Başına Tohum Verimi (g)}

Bitki başına tohum veriminde sadece ekim normu bakımından istatistiki bakımdan önemli farklılık bulunmuştur (Çizelge 3). Bu parametre bakımından en yüksek değer en düşük ekim normunun kullanılmış olduğu (6 kg/ da) parselden $3.42 \mathrm{~g} / \mathrm{bitki}$ ile elde edilmişken, en düşük değer en yüksek ekim normunun (12 kg/da) kullanıldığı parselden $2.50 \mathrm{~g} / \mathrm{bitki}$ ile elde edilmiştir (Çizelge 3). Bitki başına tohum verimi, bitkide oluşan dal sayısı ve buna bağlı olarak artan veya azalan çiçek salkımı sayısına bağlı olarak ortaya çıkmaktadır. Bu nedenle bitkide dal sayısını ve çiçek salkımı sayısı üzerinde pozitif yönde etkide bulunan ekim normu uygulaması aynı zamanda bitki başına tohum verimi üzerinde de pozitif bir etkide bulunmuştur. Bu da bitki başına artan birim alanın etkisiyle artan dal, çiçek salkımı ve tohum sayısıyla açıklanabilir.

\section{Tohum Ağırlığı (g)}

1000 tohum ağırlığı üzerinde yılların, ekim normlarının ve yıl $\times$ ekim normlarının etkisi istatistiki anlamda önemli bulunmuştur (Çizelge 3). 2013 yılına ait 1000 tohum ağırlığı değerleri (32.29 g) 2014 yılına kıyasla $(28.02 \mathrm{~g})$ daha yüksek bulunmuştur. Bu ise yıllara bağlı olarak değişen iklim koşullarıyla açıklanabilir. İki yılın ortalaması olarak ekim normlarının 1000 tohum ağırlığı üzerindeki etkisi incelendiğinde en yüksek değer dekara en az tohumluğun atıldığı (6 kg/da) parselden $33.02 \mathrm{~g}$ ile alınırken, en düşük değer ise dekara en çok tohumluğun atıldığı (12 kg/da) parselden 27.26 $\mathrm{g}$ ile alınmıştır. Bu durum birim alana atılan tohum sayısının artması ile artan bitki sayısına karşılık üretilen tohumların bir miktar küçülmüş olmasıyla açıklanabilir (Çizelge 3).

Yillar $\times$ ekim normu interaksiyonu incelendiğinde ise en yüksek değer $36.50 \mathrm{~g}$ ile 6 kg/da ekim normundan 2013 yılından alınırken, en düşük değer ise $26.93 \mathrm{~g}$ ile 2014 yılının 12 kg/da ekim normundan alınmıştır. Diğer taraftan yılların ekim normlarının ve çeşitlerin ortalaması olarak 1000 tohum ağırlığı $30.16 \mathrm{~g}$ olarak tespit edilmiştir (Çizelge 3).

Çalışmadan elde edilen 1000 tohum ağırlığı değerleri (25.13-36.93 g) Okudan (2015)'ın değeri olan 18.7- 24.2 g'dan yüksek iken, Tseng ve Huang (1992)'ın bildirdiği 33.8-45.5 g değerden düşük kalmıştır. Diğer taraftan 1000 tohum ağırlığına ait çalışmadan elde edilen değerler Yavuz ve ark (2016)'nın bildirmiş olduğu 25.6-30.7 g değerleri ile uyum içerisindedir.

\section{Dekara Tohum Verimi (kg/da)}

Dekara tohum verimi üzerinde çalışmanın yürütüldüğü yılların, çeşitlerin ve farklı ekim normlarının önemli düzeyde etkisinin olduğu tespit edilmiştir (Çizelge 3). 2014 yılından (103.40 kg/da) 2013 yılına kıyasla (81.95 $\mathrm{kg} / \mathrm{da}$ ) dekara daha yüksek tohum verimi alınmıştır. Bu durumda 2014 yılının Mayıs ve Haziran aylarında alınan yağışın 2013 yılının aynı aylarında alınan yağışa kıyasla iki katına yakın yüksek olmuş olmasıyla ve diğer iklim faktörlerindeki farklılıkla açıklanabilir (Çizelge 2).

İki yılın ortalaması olarak çalışmada kullanılan çeşitler kıyaslandığında Aktaş $(96.80 \mathrm{~kg} / \mathrm{da})$ çeşidinin Güneş (88.55 kg/ da) çeşidinden daha yüksek verim verdiği belirlenmiştir (Çizelge 3). Çeşitlerin ortaya koymuş olduğu bu performans farklılığı ise çeşitlerin genotip farklılığı ile açıklanması mümkündür.

Ekim normları kıyaslandığında ise en yüksek dekara tohum verimi $12 \mathrm{~kg} / \mathrm{da}$ ekim normunun kullanıldığı parselden 127.40 kg/ da ile alınırken, en düşük verim ise $6 \mathrm{~kg} / \mathrm{da}$ ekim normundan $59.80 \mathrm{~kg} / \mathrm{da}$ ile alınmıştır. Bu durumda birim alana atılacak olan tohumluğun artışıyla birim alana bitki sayısının arttığını ve buna bağlı olarak da dekara tohumluk veriminin artmasıyla açıklanabilir.

Yılların, çeşitlerin ve ekim normlarının genel ortalaması olarak ise $92.68 \mathrm{~kg} / \mathrm{da}$ verim elde edilmiştir (Çizelge 3). Çalışmamızda genel ortalama olarak elde edilen dekara tohum verimi (92.68 kg/da) değeri, Okudan (2015)'ın bildirdiği 51-125 kg/da değerleri ile uyum gösterirken, Tseng ve Huang (1992)'ın bildirdiği 132-234 kg/da değerinden, Kara (2014)'nın bildirdiği 146-159 kg/da değerinden ve Sobhani ve ark. (2014)'un bildirdiği 166-242 $\mathrm{kg} / \mathrm{da}$ verim değerinden düşük bulunmuştur. Topal ve ark (2012)'nın bildirmiş olduğu 17.10-46.59kg/da'dan yüksek bulunmuştur. Diğer taraftan ise Yavuz ve ark. (2016)'nın Aydın ekolojik koşullarında yürütmüş oldukları çalışmada tohum veriminin 244-288 kg/da arasında değiştiğini ve en uygun tohumluk miktarını ise $8 \mathrm{~kg} / \mathrm{da}$ olarak bildirmişlerdir. Janos ve Gocs (2009)'ın karabuğday bitkisi için $\mathrm{m}^{2}$ 'ye en uygun bitki miktarını belirlemek için yapmış oldukları çalışmada en yüksek tohum verimini (196.3 kg/da) m²'ye 375 bitkiden (10-12 $\mathrm{kg} / \mathrm{da}$ ) elde ettiklerini bildirmişlerdir. Bu durum da çalışmaların yapıldığı bölgelerin, iklim ve 
toprak özelliklerinin ve çalışmalarda kullanılan bitki materyallerinin genotipik farklılıklarıyla ve çalışmalarda gübre uygulaması yapılıp yapılmamış olmasıyla açıklanabilir.

\section{Sonuç}

İki yıllık çalışmadan elde edilen değerlerin tümü birlikte incelendiğinde Eskişehir koşullarında daha yüksek verimli karabuğday üretiminin yapılabilmesi için Aktaş çeşidinin kullanılmasının ve ekim normu olarak da 12 kg/ da tohumluk kullanımı tavsiye edilmektedir.

\section{Kaynaklar}

Acar R., GüneşA. ve Aktaş A.H., 2012. Karabuğdayla sağlıklı yaşama merhaba. Bahri Dağdaş Uluslararası Tarımsal Araştırma Enstitüsü. Karabuğday Proje Bülteni, 1:1-2. Konya

Anonim, 2015. https://en.wikipedia.org/wiki/ Buckwheat (Erişim tarihi:28.06.2015)

Bagheri H., Sharghi Y. and Yazdani M., 2011.The study of planting density on some agronomic traits of spring canola cultivars. Australian Journal of Basic and Applied Sciences, 5(10):1302-1305

Bonafaccia G., Marocchini M. and Kreft I., 2003. Composition and technological properties of the flour and bran from common and tartary buckwheat Food Chemistry, 80(1):9-15

Düzgüneş O., Kesici T., Kavuncu O. ve Gürbüz F. 1987. Araştırma ve Deneme Metodları (İstatistik Metodları). Ankara Üniversitesi Ziraat Fakültesi Yayınları:1021. Ankara

Geçit H.H., Çiftçi C.Y., Emeklier Y., İkincikarakaya S., Adak M.S., Ekiz H., Altınok S., Sancak C., Sevimay C.S. ve Kendir H., 2009. Tarla Bitkileri, Ankara Üniversitesi Ziraat Fakültesi Yayın No:1569, Ders Kitabı: 521, Ankara

Inamullah I., Saqıb G., Ayub M., Khan A.A., Anwar S. and Khan S.A., 2012.Response of Common Buckwheat to Nitrogen and Phophorus Fertılızatıon.Sarhad J. Agric., 28(2):171-178

Janos L. and Gocs L., 2009. Second Crop buckwheat in Nyırseg regions. Analele Universităţii din Oradea, Fascicula:Protecţia Mediului, 19:190-195

Kaleem S., Hassan F.U., Farooq M., Rasheed M. and Munir A., 2010. Physio-morphic traits as influenced by seasonal variation insunflower; Areview. Int. J. Agric. Biol., 12:468-473

Kara N., 2014. Yield and mineral nutrition content of buckwheat (Fagopyrum esculentum Moench): the effect of harvest times, Süleyman Demirel Üniversitesi Ziraat Fakültesi Dergisi, 9(1):85-94
Kim J., Wieslander G. and Norback D., 2004.Allergy /Intolerance to Buckwheat and Other Food Products among Swedish subjects with celiac disease. proceedings of the $9^{\text {th }}$ International Symposium on Buckwheat, Prague, pp:705709

Kreft S., Knapp M. and Kreft I., 1999. Extraction of rutin from buckwheat (Fagopyrum esculentum Moench) seeds and determination by capillary electrophoresis. Journal of Agricultural and Food Chemistry, 47(11):4649-52

Min W., Yi-min W. and Jin-min G., 2004. Analysis of fatty acid and unsaponifiable matter from tartary buckwheat oil and buckwheat oil by GC/MS. Proceedings of the $9^{\text {th }}$ International Symposium on Buckwheat, Prague, p:721729

Ohnishi O., 1994. Buckwheat in Karakoram and the Hindukush. Fagopyrum, 14:17-25

Okudan D., 2015. Farklı azot dozlarının karabuğdayın (Fagopyrum esculentum Moench) tane verimi ve kalitesine etkisi. Süleyman Demirel Üniversitesi Fen Bilimleri Enstitüsü. (Yüksek Lisans Tezi/ Basılmamış), Isparta

Özer H., 2003. The effect of plant population densities on growth, yield and yield components of two spring rapeseed cultivars. Plant Soil Environ., 49(9):422-426

Sobhani M.R., Rahmikhdoev G, Mazaheri D. and Majidian M., 2014. Influence of different sowing date and planting pattern and $\mathrm{N}$ rate on buckwheat yield and its quality. Australian Journal of Crop Science, 8: 1402-1414

Sobhani R.M., Rahmikhdoev G., Mazaheri D., Majidian M., 2012.Effects of sowing date, cropping pattern and nitrogen on CGR, yield and yield component summer sowing buckwheat (Fagopyrum esculentum Moench), Journal of Applied Environmental and Biological Sciences, 2(1): 35-46

Şehirali S. ve Özgen M., 2010. Bitki Islahı (Düzeltilmiş 4. Baskı), Ankara Üniversitesi Ziraat Fakültesi Yayın No:1582, Ders Kitabı: 534, Ankara

Topal İ., Güneş A., Koç, H., Acar R., Kara İ., Ercan, B. ve Gummadov N., 2012. Konya koşullarında farklı ekim sıklıklarının karabuğday (Fagopyrum esculentum Moench.)'da verim ve bazı verim unsurlarına etkisi, Tıbbı ve Aromatik Bitkiler Sempozyumu 13-15 Eylül, Tokat, s. 234-237

Tseng, S.H. and Huang, S.C., 1992. Studies on Increasing grain yield of buckwheat in Taiwan. http://tdares.coa.gov.tw/files/web_ articles_files/tdares/9573/3731.pdf. (Erişim Tarihi: 12.07.2015). 
Katar and Katar "Determination of Sowing Rates of Different Buckwheat (Fagopyrum esculentum Moench) Cultivars U nder Eskişehir Ecological Conditions"

Yavuz H., Yiğit A. ve Erekul O., 2016. Farklı ekim sıklıklarının karabuğday'da (Fagopyrum esculentum Moench.) verim ve bazı tane kalitesi özelliklerine etkisi. Adnan Menderes Üniversitesi Ziraat Fakültesi Dergisi; 13(2) : $17-22$ 